\title{
Epidemiological response to a suspected excess of cancer among a group of workers exposed to multiple radiological and chemical hazards
}

\author{
H Baysson, D Laurier, M Tirmarche, M Valenty, J M Giraud
}

\begin{abstract}
Objective-An excess of cancer was suspected by workers of the metallurgy department at the French Atomic Energy Commissariat (CEA) after several deaths from cancer were reported in 1983 and 1984. After a descriptive study performed by the CEA in 1985 the results of which were not conclusive enough to put an end to the controversy, the present cohort study was undertaken in 1989.

Methods-As no specific exposure, or a precise cancer site was suspected, it was decided to include all subjects who had worked at the metallurgy department for at least 1 year between 1950 and 1968. The cohort was followed up to 31 December 1990. Individual occupational exposures were determined retrospectively for each year from 1950 to 1990 , both qualitatively (annual job, and hazard records, and assistance from former workers) and quantitatively (for external radiation). On the basis of these exposures, three types of occupational tasks were identified: handling of chemicals, radionuclides, and external radiation. Standardised mortality ratios (SMRs) were calculated to estimate the risk of death, and the existence of an association between risk of cancer and each of the three tasks was tested.
\end{abstract}

Results-The cohort included 356 workers, followed up for an average of 30 years (total of 10820 person-years). The number of deaths from all causes and from all cancer sites were respectively 44 and 21 . No excess of cancer deaths was found for the study period (SMR 0.77), nor was there a peak in 1983-4. The risk of death from all cancer sites increased with the duration of exposure to chemicals.

Conclusion-The results do not justify the workers' impression of an excess of cancer. They suggest, however, that the duration of work at some tasks that involved handling chemicals may be an indicator of risk of cancer. Communication to the workers during the study played an important part in reducing their concern, contributing to their better understanding of the results.

(Occup Environ Med 2000;57:188-194)

Keywords: epidemiology; cancer; mortality; cluster; occupational exposures
A suspicion of an excess of cases of cancer (a cluster) often begins among workers who have the impression that cases of cancer are occurring with inordinate frequency in their group, ${ }^{1}$ an epidemiological study may be requested. These cluster studies, however, raise several methodological problems, due in particular to the small size of the study population concerned and the lack of any specific aetiological hypothesis to explain the cluster. Accordingly, it is rare that it can be clearly concluded that a causal relation exists between the observed excess of cases of cancer and a particular risk factor. For this reason, some authors stress that cluster studies are most useful as part of occupational surveillance rather than as aetiological research. ${ }^{2}$ These studies do, however, help generate hypotheses that can then be confirmed or disproved by studies of other worker populations, and thus play a central part in occupational epidemiology. ${ }^{3}$

This mortality study of the workers in the metallurgy department of the French Atomic Energy Commissariat (CEA) shows the usefulness and the limitations of epidemiology in dealing with the worries of a group of workers about the carcinogenic risks of their occupational exposures. This article presents the objectives, methods, and principal results, and then discusses them in the light of the methodological limitations inherent in cluster studies.

The metallurgy department was a small unit of the French Atomic Energy Commissariat (CEA) with about 100 workers. The primary activity of the metallurgy department involved research on the metallurgy of uranium. Occupational exposures were multiple and heterogeneous; workers handled various chemicals and were potentially exposed to ionising radiation, both externally from radioactivity in the working environment and internally from handling radionuclides.

This group of workers was stable and workers had worked together for a long time and knew each other well. Even after retirement, most exworkers kept in contact so that they had the chance to know about some cases of cancer among them. In 1983-4, after three deaths from cancer were known to have occurred, there was a general feeling among workers that there was "too much" cancer in their group. Workers in the metallurgy department raised the question of occupational carcinogenesis to their representatives and then to the medical department.

In 1985, in response to these concerns, the CEA performed a first descriptive survey. The 
Institute for Protection and Nuclear Safety (IPSN) gave statistical support. Only a subset of workers was included in this study, based on imprecise causes of death and an approximate evaluation of the duration of employment. An excess of deaths from cancer was found, which was not significant. No information on occupational exposures was considered. Because of the limitations of this first study, it was decided in 1989 that IPSN would undertake an epidemiological study to find whether there was an excess of deaths from cancer in this population. More precisely, three main questions had to be answered. Was there really a peak of cancer deaths in 1983-4 in this population, as workers suspected? Was there, on the whole, an excess risk of cancer among them? Finally, was there a relation between the risk of death from cancer and their occupational exposures?

Because no systematic collection of mortality data had been realised in the past, a cohort study was performed, which considered all deaths and reconstructed past occupational exposures as exactly as possible.

As no specific exposure was suspected to cause these cancers, it was decided to test the hypothesis of an association between excess number of deaths from all cancer sites and some of the tasks performed in this department.

\section{Materials and methods \\ DATA COLLECTION}

Definition of the cohort

Personnel records at CEA were used to define the cohort, which comprised all subjects who had worked at the metallurgy department for at least 1 year between 1950 and 1968. In 1968, workers from other departments were moved to the metallurgy department. As it was impossible to reconstruct the professional history of these workers, who had undergone various types of occupational exposures in the past, the inclusion period was only up to 1968. This allowed a long enough latency period between exposure and diagnosis. The completeness of the list thus obtained was verified with representatives of the workers and discussed with former workers in the metallurgy department. The date of the end of the study was set at 31 December 1990.

\section{Vital status and causes of death}

The vital status of the workers was ascertained from information provided by occupational physicians who monitor workers' health regularly throughout their career and by the registry office of the workers' birthplaces. The vital status of French citizens born abroad was ascertained from information provided by the registry office of the Ministry of Foreign Affairs.

The causes of death were obtained from the French national file of causes of death administered by the French National Institute for Health and Medical Research (INSERM), which contains all deaths in France from 1968 onward. For the deaths not found in the file (in particular those that occurred before 1968), the causes of death were provided directly from information from the CEA medical department. Causes of death were coded according to the 9th revision of the international classification of diseases (ICD-9). ${ }^{4}$

\section{Assessing occupational exposures}

Many and heterogeneous occupational exposures potentially arise from metallurgical research in the nuclear field: use of chemicals, external exposure to ionising radiation, and internal contamination from handling radionuclides.

Individual exposures were assessed retrospectively for each year of work in the metallurgy department. Two sources of information were used: job and hazard forms contained in the medical files and information from former workers of the department. The job and hazard forms should trace the career of each worker and identify chemical and radiological hazards to which the worker might have been exposed each year. These forms, however, were introduced at the end of the 1950s and were not systematically completed each year. They were therefore insufficient for complete epidemiological monitoring. For this reason, discussions with former workers of the department were crucial to fill in and complete this information. In particular, the assessment of occupational exposures from 1950 to 1960 would have been impossible without their assistance. For each year, individual exposures to about 30 different specific products were reconstructed in a qualitative way (exposed or not exposed).

External radiation received by these workers as part of their activity in the metallurgy department was also reconstructed from individual dosimetric records: individual monitoring of workers subjected to external exposure to ionising radiation has been in effect since 1950. The doses of $\gamma$ rays received have been recorded annually for each worker's entire career.

\section{STATISTICAL ANALYSIS}

Calculating the standardised mortality ratio

The observed number of deaths was compared with the expected number of deaths by calculating the standardised mortality ratio (SMR) - that is, the ratio of observed to expected deaths. ${ }^{5}$ Expected mortality was calculated by applying the national mortalities, by sex, 5 year age class, and calendar year (1950-90) to the number of corresponding person-years. With this so called indirect standardisation method, risk estimates can be adjusted for sex, age, and calendar year, to be comparable among different groups. The hypothesis of an excess risk (SMR>1) was tested, assuming that the number of observed deaths followed the Poisson distribution. The $90 \%$ CI was calculated with the method based on Byar's formula and described by Breslow and Day. ${ }^{5}$

Study of mortality from all cancer sites as a function of the duration of exposure

Because the initial request did not hypothesise any specific causal exposure, and as the cohort 
Table 1 Cohort characteristics

Workers (n)

Men (n (\%))

Alive at the 31 December 1990 (n (\%))

Lost to follow-up (n (\%))

Dead at the 31 December 1990 (n (\%))

Of unknown causes (n (\%))

Mean (range) age at entry into cohort

Mean (range) age of those alive on 31 December 1990

Year of entry (range)

Year of end of follow up (range)

Mean duration of follow up (y)

Total person-years (n)

Mean (range) duration of work in the Metallurgy Department (y)
356

$307(86.2)$

$288(80.9)$

$24(6.7)$

$44(12.4)$

$30.1(16-57)$

$60.9(43-91)$

(1950-68)

(1955-90)

$30.4(2-40)$

10820

$16.9(1-37)$

was relatively small (a few hundred), the occupational exposures identified were classified in three groups reflecting three different types of activity: use of chemicals, external exposure to ionising radiation, and handling radionuclides. The chemicals group included exposure to chemicals, but also some other potentially toxic products such as asbestos, graphite, and soldering products. External radiation involved exposure to $x$ rays, as well as $\gamma, \beta$, and neutron radiation. The radionuclides used (thorium and natural and enriched uranium) could have caused internal contamination. For each type of exposure, the periods of exposure (beginning to end) and the total number of years of exposure were ascertained.

Classification according to duration of exposure divided workers into groups with essentially equivalent numbers of person-years per group (division into percentiles). This choice was made to obtain an objective definition of the different groups and to minimise the uncertainty around the risk estimates. For exposures to chemicals, external radiation, and radionuclide handling, six groups of exposure duration were defined: 0 years, $1-4$ years, 5-9 years, $10-14$ years, $15-19$ years, and $\geqslant 20$ years.

The increased risk of death from cancer as a function of duration of exposure was examined with three different methods to verify their concordance and the reliability of the results. The Poisson trend test ${ }^{5}$ was applied to the SMR specific to each exposure group. The dose-effect relation was modelled with Poisson regressions. ${ }^{6}$ Two reference groups were used: the national population (external reference) and a non-exposed group within the cohort (models stratified for age, sex, and calendar year). These analyses were carried out separately for each type of exposure; use of chemicals, external exposure to ionising radiation, and handling radionuclides.

Study of mortality from all cancer sites as a function of the cumulative $\gamma$ dose

The same analytical methods were used to test the relation between an excess risk of cancer and cumulative external radiation expressed in $\mathrm{mSv}$. Five dose groups were defined such that each group contained roughly equivalent numbers of person-years: no dose, $0.35-1.40$ $\mathrm{mSv}, 1.41-3.95 \mathrm{mSv}, 3.96-10.25 \mathrm{mSv}$, and $\geqslant 10.26 \mathrm{mSv}$.

Table 2 Details of occupational exposures

\begin{tabular}{|c|c|c|}
\hline \multirow[b]{2}{*}{ Occupational exposures } & \multicolumn{2}{|c|}{ Workers exposed $\geqslant 1 y$} \\
\hline & $n$ & $\%$ \\
\hline \multicolumn{3}{|l|}{ Handling of chemicals: } \\
\hline Total & 191 & 100.0 \\
\hline Alcohols & 30 & 15.7 \\
\hline Aromatic amines & 2 & 1.0 \\
\hline Asbestos & 7 & 3.7 \\
\hline Beryllium & 66 & 34.6 \\
\hline Ketones & 86 & 45.0 \\
\hline Chrome & 10 & 5.2 \\
\hline Graphite & 34 & 17.8 \\
\hline Mercury & 21 & 11.0 \\
\hline Oils & 28 & 14.7 \\
\hline Nickel & 23 & 12.0 \\
\hline Lead & 30 & 15.7 \\
\hline Aromatic solvents & 35 & 18.3 \\
\hline Chlorinated solvents & 126 & 66.0 \\
\hline Soldering products & 38 & 19.9 \\
\hline Toluene or benzene & 84 & 44.0 \\
\hline Others & 13 & 6.8 \\
\hline \multicolumn{3}{|l|}{ Handling of radionuclides: } \\
\hline Total & 255 & 100.0 \\
\hline Thorium & 57 & 22.4 \\
\hline Enriched uranium & 52 & 20.4 \\
\hline Natural uranium & 240 & 94.1 \\
\hline Activation products & 18 & 9.4 \\
\hline Fission products & 63 & 33.0 \\
\hline Others & 10 & 3.9 \\
\hline \multicolumn{3}{|c|}{ External exposure to ionising radiation: } \\
\hline Total & 253 & 100.0 \\
\hline$x$ & 129 & 51.0 \\
\hline$\gamma$ & 192 & 75.9 \\
\hline$\beta$ & 235 & 92.9 \\
\hline Neutrons & 66 & 26.1 \\
\hline \multicolumn{3}{|l|}{ External dosimetry: } \\
\hline Annual non-zero doses & 262 & 73.6 \\
\hline
\end{tabular}

Software

Data management and statistical analysis were performed with SAS. ${ }^{7}$ The Poisson regression modelling used the Amfit module of Epicure. ${ }^{8}$

\section{Results}

COHORT DESCRIPTION

Characteristics of the cohort

In the study were 356 workers ( 307 men, 49 women). The number of persons-years was 10820 from a mean duration of follow up of 30 years (table 1). The vital status of 24 workers $(6.7 \%)$ could not be ascertained. In all, 44 deaths were recorded in the cohort. Despite extensive research, the causes of six deaths $(14 \%)$ remained unknown. These were mainly deaths that occurred before 1968 or out of France.

\section{Occupational exposures}

The occupational exposures grouped into three classes (chemicals, radionuclides, external radiation) are listed in table 2 .

Within the 356 workers included, the following information was collected from job and hazard forms contained in the medical files:

- 191 Workers (54\%) had been exposed for at least 1 year to chemicals, with a mean duration of exposure of 12 years

- 255 Workers (72\%) handled radionuclides, principally natural uranium. The mean duration of exposure to radionuclides was 11 years

- 253 Workers (71\%) had been exposed for at least 1 year to external radiation, with a mean duration of exposure of 11 years 


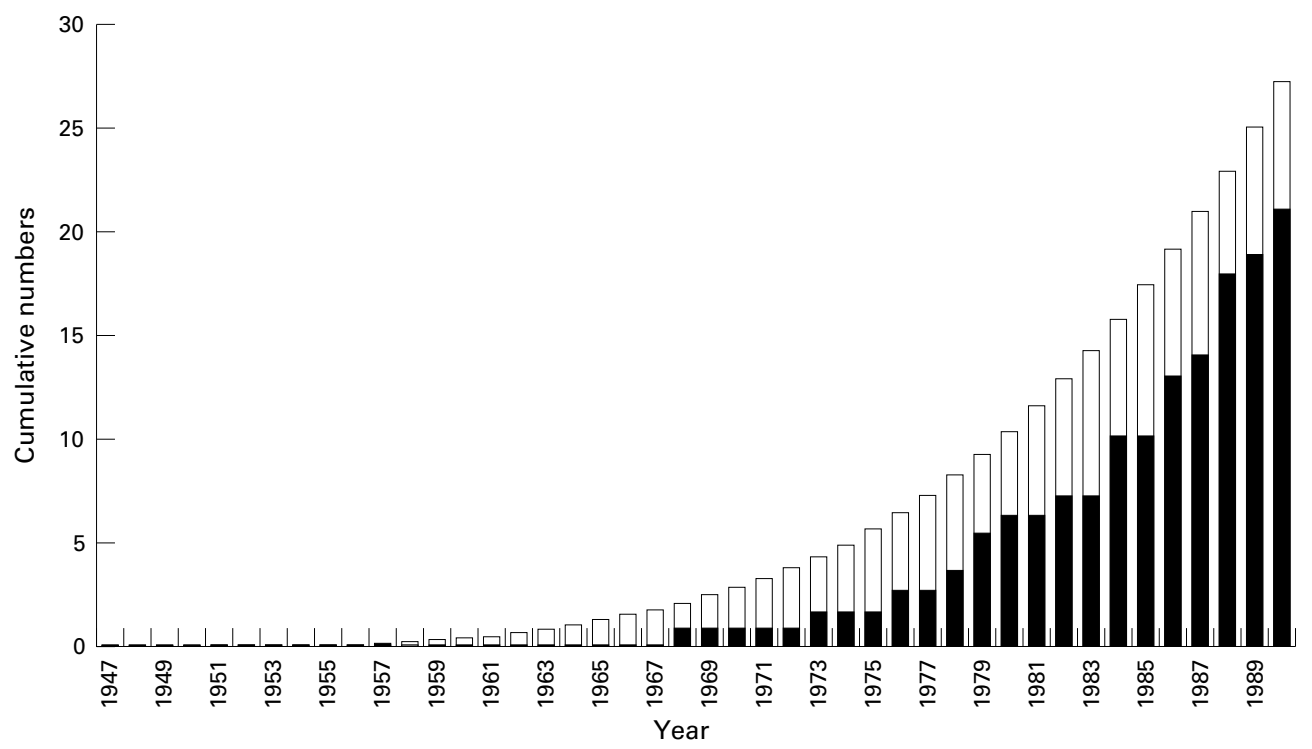

Figure 1 Numbers of observed ( $\mathbf{\square}$ ) and expected ( $\square$ ) deaths from all cancer sites.

- 72 Workers $(20 \%)$ had not been exposed to any of the three types of occupational exposure

- Conversely, $45 \%$ of the workers had faced all three types of occupational exposure simultaneously for at least 1 year.

From individual dosimetric records 262 workers $(74 \%)$ were identified with a non-zero annual dose recorded for at least 1 year. Among these workers, the mean cumulative dose for the period $1950-90$ was $8.7 \mathrm{mSv}$, with a maximum of $85.2 \mathrm{mSv}$. The maximum annual dose was $25 \mathrm{mSv}$. Some of these workers had been exposed to very low doses and thus were not identified as exposed to external radiation in the job and hazard forms contained in their medical file.

\section{MORTALITY}

Trend of cancer deaths over time

The primary aim was to test the hypothesis of an excess of cancer deaths in 1983-4. In the first approach we compared the trend of the observed cancer deaths over time with that expected if the cohort members had the same

Table 3 Mortality by cause: observed and expected number of deaths, SMR $(90 \%$ CI)

\begin{tabular}{lllll}
\hline Causes of death (ICD-9) & Observed & Expected & SMR & 90\% CI \\
\hline All causes (1-999) & 44 & 95.3 & 0.46 & 0.35 to 0.59 \\
All types of cancer (140-208) & 22 & 28.6 & 0.77 & 0.52 to 1.10 \\
Cancers of the respiratory system (160-164) & 9 & 8.4 & 1.07 & 0.56 to 1.87 \\
Cancers of the digestive system (150+153-154) & 4 & 4.5 & 0.89 & 0.30 to 2.03 \\
Multiple myeloma (203) & 2 & 0.2 & 8.38 & 1.44 to 26.2
\end{tabular}

${ }^{\star}$ Reference mortality for the national population.

Table 4 Relation between occupational exposures and risk of death from all cancer sites

\begin{tabular}{|c|c|c|c|c|c|}
\hline & \multirow{2}{*}{$\begin{array}{l}\text { Trend } \\
\text { test }\end{array}$} & \multicolumn{2}{|c|}{$\begin{array}{l}\text { External } \\
\text { regression }\end{array}$} & \multicolumn{2}{|c|}{ Internal regression } \\
\hline & & $E R R$ & $p$ Value & $\overline{E R R}$ & $p$ Value \\
\hline \multicolumn{6}{|l|}{ Duration of exposure (y): } \\
\hline Handling chemicals & 0.001 & 0.25 & 0.005 & 0.18 & 0.003 \\
\hline Handling radionuclides & 0.05 & 0.11 & 0.071 & 0.07 & 0.13 \\
\hline External exposure to ionising radiation & 0.28 & 0.04 & 0.339 & 0.02 & 0.53 \\
\hline \multicolumn{6}{|l|}{ Cumulative doses (mSv): } \\
\hline External dosimetry & 0.56 & 0.0001 & 0.57 & 0.006 & 0.80 \\
\hline
\end{tabular}

ERR=Excess relative risk per unit of exposure. mortality as the national population. Figure 1 presents the distribution over time of the cumulative observed and expected numbers of cancer deaths from 1950 to 1990 .

There was no peak in cancer deaths in 1983-4. Moreover, it seems that, over time, the number of cancer deaths observed in the cohort has always been lower than the number expected from the national rates. Compared with the national population, there was no excess of cancer mortality during this period.

\section{Mortality by cause}

Table 3 shows the results observed for all causes of mortality, for deaths from all cancer sites, and for deaths from specific types of cancer. There was a deficit in deaths from all causes (SMR 0.46, p<0.05, one sided test) and to a lesser extent for the deaths from all cancer sites ( $\mathrm{SMR} 0.77, \mathrm{p}>0.05$, one sided test). The analysis by cancer site gave an SMR $>1$ for respiratory cancers, but the number of deaths observed did not differ significantly from the number expected ( $p>0.05$, one sided test). There was a significant increase in the risk of death from multiple myeloma (SMR 8.38, $p=0.02$, one sided test), but this result was based on only two observed cases. Due to the small numbers, none of these results reached significance.

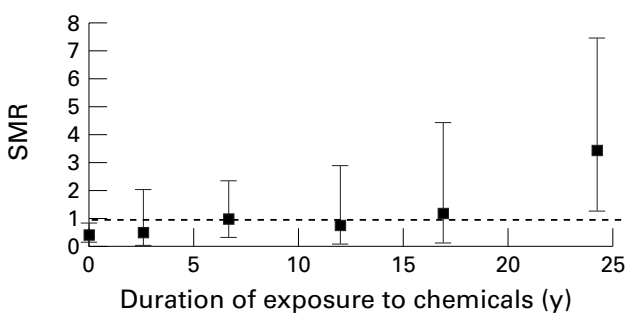

Figure 2 Mortality from all cancer sites by duration of exposure to chemicals. 
Table 5 Mortality from all types of cancer as a function of the period of exposure: (SMR $(90 \% C I))$

\begin{tabular}{|c|c|c|c|c|}
\hline & \multicolumn{2}{|c|}{ Before 1960} & \multicolumn{2}{|c|}{ After 1960} \\
\hline & $S M R$ & $90 \% C I$ & $S M R$ & $90 \% C I$ \\
\hline $\begin{array}{l}\text { Assignment to the Metallurgy Department } \\
(\mathrm{n}=356)\end{array}$ & 0.87 & 0.56 to 1.29 & 0.50 & 0.17 to 1.14 \\
\hline First exposure to chemicals $(n=191)$ & 1.24 & 0.69 to 2.05 & 0.94 & 0.41 to 1.85 \\
\hline
\end{tabular}

Mortality from all cancer sites as a function of exposure

For each type of exposure, the results of the three methods used (trend test, Poisson regressions with external and internal reference groups) are on the whole consistent (table 4).

For external radiation, no relation was established between the risk of death from all cancer sites and duration of exposure $(p>0.20$, whatever the method used). The conclusion was the same when we considered the relation with cumulative dose $(p>0.50$, whatever the method used). However, the doses received by workers were low; the mean cumulative dose for the period 1950-90 was $8.7 \mathrm{mSv}$.

The risk of death from all cancer sites did seem to be related to the duration of exposure to radionuclides according to the trend test, but this finding was of borderline significance, and neither of the two regression methods found a significant result.

The results show that the risk of death from all cancer sites increased with the duration of exposure to chemicals (table 4). None the less, the slope was influenced by an increased risk for the group with the highest duration of exposure (SMR 3.42 in the group with $>20$ years of exposure, fig 2). This finding led us to analyse the effect of the period of exposure. Table 5 shows that the SMR for those first exposed before 1960 was 1.24 , although it was only 0.94 for those first exposed after 1960 (the SMR (90\% CI) calculated for all 191 workers exposed to chemicals was 1.11 (0.71 to 1.67$)$ ). Although neither of these two estimations was significantly different from unity, this suggested that the period of exposure has an effect. There was a similar indication when we examined the period of employment in the metallurgy department. It therefore seems that at least part of the relation between duration of exposure to chemicals and risk of death from all cancer sites may be explained by an increased risk associated with exposure a very long time ago. Workers with a high duration of exposure are also those who have been exposed to working conditions that prevailed in the 1950 s.

\section{Discussion}

RESPONSE TO THE WORKERS' CONCERN

The question of an excess of cancer deaths was raised in 1984. The timescale shows the difficulty of an answer to such a workers' concern. The first analysis, launched in 1985, was based only on existing information, and was unable to answer questions about a potential link with occupational activities. As the studied population was not exhaustive, it was difficult to measure the level of risk. In 1989, in response to persisting concerns of the workers, the CEA medical department asked the IPSN to undertake the present epidemiological study. First results were presented in 1996 to workers and to the Hygiene and Safety Commission of the CEA, grouping representatives of the CEA and of the trade unions. The final version of the IPSN report was published in 1998, approved by all parties. ${ }^{10}$

This study responded to the concerns of the workers in the metallurgy department. It showed that there was no excess of cancer in 1983-4 and that in this cohort, death from all cancer sites was not greater than that expected, based on national mortalities.

During the collection of the data and the analytical phase of the study, intermediate meetings were organised by the team of epidemiologists, to keep the workers informed about the progress of the study and to answer their questions. ${ }^{2}$ Communication to the workers of the metallurgy department during the study played an important part in the reduction of their concern by contributing to a better understanding of the results.

\section{Size of the study population}

When conducting a study in response to a suspected excess of cases in a given population, the epidemiologist has a study population of given size. This raises several methodological problems related to a lack of statistical power, as various authors have pointed out. ${ }^{1211}$

Here, the study population was limited, focusing as it did on a particular group of CEA workers. However, the weak statistical power of the study was partially compensated by a long period of epidemiological follow up (1950-90) bracketing the period of alert (1983-4) as widely as possible. The inclusion period (1950-68) beginning long before this period of alert, was deliberately chosen to take into account the longest possible latency period between exposure and diagnosis ${ }^{2}$; and to permit the cohort to reach age groups at which cancers normally occur.

Finally, the number of person-years was such that there was a power of $80 \%$ to detect a relative risk of 1.5 for deaths from cancer. But such an excess was not expected. The study had only a power of $50 \%$ to detect a relative risk of 1.3 for deaths from cancer. For specific causes of death, only extreme relative risks would have been detected.

We also tried to compensate for the weak power by making methodological choices that limited the risk of error and validated the results. These included an objective definition of the duration of exposure groups and the use of several analytical methods.

\section{Choice of the investigation protocol}

The approach most often recommended to assess the existence of a suspected cancer excess is a simple verification of the number of cases reported, based on death certificates, medical files, and cancer registries. ${ }^{2}$ A more rigorous and informative method entails conducting a cohort study. The vital status and occupational exposures of all members of the cohort, whatever their current occupational 
status, can thus be examined. Setting up such a study is not always possible, because incomplete data prevent an adequate definition of the study population or a retrospective assessment of occupational exposures. Moreover, this type of approach cannot be used if a rapid answer is desired, as is generally the case in a climate of concern: cohort studies imply results over a long period, often after several years or even decades. ${ }^{6}$ It is thus a long drawn out project that requires complex and expensive logistics. Because of the delay inherent in obtaining results from a cohort study, several authors recommend a stepwise investigation ${ }^{211}$ that can provide a rapid response to the workers involved and can progressively determine the reality of a cancer excess and the plausibility of its association with occupational exposures.

In our case, a first descriptive survey was conducted in 1985. But because of its limitations, this first survey was not conclusive enough to put an end to the controversy. In 1989 a retrospective cohort study was undertaken, thanks to CEA personnel files, an essential tool for constituting an exhaustive cohort from a specific department.

The small size of the population studied also allowed a precise reconstruction of occupational exposures from two sources of information: the job and hazard forms contained in the medical files and the memory of former workers. Their collaboration at this stage of the investigation was indispensable, and was especially fruitful because the workers in the metallurgy department had worked together for a long time and knew each other well. The collection of data for each worker included in this study was none the less ponderous and could not have been performed for a much larger study. Other approaches-for example, the development of a job exposure matrix ${ }^{12}-$ may be preferred for retrospective assessment of occupational exposures, mainly when considering a large cohort of workers.

\section{Choice of the reference population}

To verify the possible existence of an excess of cancer for the entire period 1950-90, the national population was chosen as a reference because only national mortalities are available by age and sex over the whole period in France; they also have the advantage of being reliable. Use of the national population presents disadvantages, however, because there are substantial disparities in lifestyle, environment, etc. Here, compared with the national population, the cohort experienced a relatively low number of deaths, both overall and from causes other than cancer (table 3 ). This may be explained by a particularly strong healthy worker effect in this population, which has already been noted in several nuclear worker studies. ${ }^{13}{ }^{14}$ This effect is related to the fact that workers are generally in good health and receive regular medical follow up. ${ }^{15}$ In our study, the healthy worker effect is quite substantial for the overall deaths from all causes (SMR 0.46). It is less extensive for the cancer deaths, regardless of type (SMR 0.77). One hypothesis might be that the healthy worker effect plays a greater part in diseases which can be treated (thanks to better access to health care and early screening) than in cancers.

In our study, the choice of an internal reference group of cohort members with no exposure allowed comparisons without interference from the healthy worker effect. ${ }^{11}$

\section{Results}

The causes of six deaths remain unknown. These were mainly deaths that occurred before 1968 or outside France. None of them occurred in 1983-4. Even if these six deaths were cancer deaths, this would have had no consequence on the results (observed 28, expected 28.6, SMR 0.98). Furthermore, these six subjects had not been exposed to any of the occupational exposures considered to define the three types of task.

The observation of an excess of deaths from multiple myeloma is in line with the findings of other epidemiological studies of workers in the nuclear industry. ${ }^{1416}$ Here, the number of deaths from this disease was too low to permit any conclusion, but because of the rarity of the disease ${ }^{17}$ the excess relative risk is consequently high.

No relation was established between the risk of cancer and the duration of external exposure to ionising radiation. The doses received by workers who were exposed for at least 1 year to external radiation were low: the mean cumulative dose for the period $1950-90$ was $8.7 \mathrm{mSv}$. In comparison, $\geqslant 4.5 \mathrm{mSv}$ could be received each year from natural background radiation. This low cumulative exposure and the low number of workers exposed to external radiation prevented finding any risk linked to exposure from external radiation. ${ }^{14}$

The results show an increase in the risk of death from any kind of cancer with the duration of exposure to chemicals. They thus underline the importance of taking exposure to chemicals into account among the occupational exposures of workers in the nuclear industry, especially in the development of job exposure matrices. ${ }^{18}$ These results, none the less, are difficult to interpret and must be considered with caution. In particular, due to the small size of the population it was not possible to analyse separately each of the chemicals involved, or to consider the combined exposure to several carcinogenic agents (chemical or radioactive substances, etc). Also, we had to test the relation between duration of exposure and the risk of death from all types of cancer together, because distinguishing between types of cancer was non-informative in view of the few cancers observed.

In general, epidemiological analytical studies attempt to test an excess risk for a given type of cancer relative to exposure to a specific substance suspected to be carcinogenic (based on experimental research). Here such an analysis was impossible due to the small size of the cohort; nor was that our initial objective. Cluster studies are, after all, primarily conducted to respond to the concern of the public or of a group of workers. From this point of view, the study had a positive impact. 


\section{Conclusion}

Despite the methodological difficulties inherent in cluster studies, the weak statistical power of this study was compensated for by an exhaustive definition of the cohort, by the establishment of a long term epidemiological retrospective follow up, by a precise reconstruction of occupational exposures, and by the use of several analytical methods. The study thus allowed us to respond to the questions raised by the workers in the metallurgy department. It showed that there was no excess of cancer in either 1983-4 or in the entire study period. Next, the results indicated that the death rate observed in the cohort from all cancer sites was not greater than that expected from the national population rates. A significant increase in the risk of death from multiple myeloma was found but was based on only two cases. Finally, the analysis by type of exposure suggests that there is a relation between the risk of death from all cancer sites and the duration of exposure to chemicals. This result cannot be considered as indicative of a causal relation but it may provide the basis for aetiological hypotheses to be tested in larger studies. By comparison with a simple census of the deaths from cancer, this cohort study allowed us to respond to the concern of the workers and to develop several aetiological hypotheses. This procedure was possible thanks to the data from CEA archives, the small size of the study population, and the collaboration of former workers in the metallurgy department. The follow up of this group of workers will continue in the future, as part of the large study of nuclear workers in France. ${ }^{18}$

We thank the medical team of CEA (Saclay) and all the former workers in the metallurgy department who made the study pos- sible. Our thanks go also to Dr Catherine Gimenez, Mr Alain Barbe, the Conseil d'Unité of the metallurgy department for their help in collecting the data.

1 Schulte PA. Investigation of occupational cancer clusters: theory and practice. Am ₹ Public Health 1987;77:52-6.

2 Frumkin H, Kantrowitz W. Cancer cluster in the workplace: an approach to investigation. F Occup Med 1987;29:949 52 .

3 Fleming LE, Ducatman AM, Shalat SL. Disease clusters: a central and on-going role in occupational health. $\mathcal{F}$ Occup Med 1991;33:818-25.

4 World Helath Organisation. Classification internationale des maladies, Révision 1975. Vol 1. Genève: WHO, 1977.

5 Breslow N, Day N. Statistical methods in cancer research. Vol II. The design and analysis of cohort studies. Lyon: II. The design and analysis of cohort studies. Lyon: (IARC Sci Publ No 82.)

6 Bouyer J, Hémon D, Cordier S, et al. Epidémiologie. Principes et méthodes quantitatives. Paris: INSERM, 1993.

7 Sas Institute. SAS language: reference, version 6, 1 st edition. Cary, NC: SAS, 1990.

8 Preston DL, Lubin JH, Pierce DA. Epicure. Seattle, WA: Hirosoft, 1990

9 Institut national de la Santé et de la Recherche Médicale (INSERM). Statistiques des causes médicales de décès. Paris: INSERM, 1990

10 Baysson H, Laurier D, Tirmarche M, et al. Etude de mortalité des travailleurs du Département de Métallurgie du Commissariat à l'Energie Atomique : 1950-1990. Fontenay-auxRoses, France: Rapport interne IPSN, Note SEGR 01, janvier 1998.

11 Fleming LE, Ducatman AM, Shalat SL. Disease clusters in occupational medicine: a protocol for their investigation in the workplace. Am f Ind Med 1992;22:33-47.

12 Bouyer J, Hémon D. Les matrices emplois-expositions. Rev Epidémiol Santé Publique 1994;42:235-45.

13 Artalejo FR, Lara SC, Manzano B, et al. Occupational exposure to ionizing radiation and mortality among exposure to ionizing radiation and mortality among
workers of the former Spanish Nuclear Energy Board. Occup Environ Med 1997;54:202-8.

14 Cardis E, Gilbert ES, Carpenter L. et al. Effects of low doses and low dose rates of external ionizing radiation: cancer mortality among nuclear industry workers in three countries. Radiat Res 1995;142:117-32.

15 Fox AJ, Collier PF. Low mortality rates in industrial cohort studies due to selection for work and survival in the industry. Br f Prev Soc Med 1976;30:225-30.

16 Smith P, Douglas A. Mortality of workers at the Sellafield plant of British Nuclear Fuels. BMF 1986;293:845-54.

17 Obrams GI, Potter M. Epidemiology and biology of multiple myeloma. Berlin: Springer-Verlag, 1991.

18 Telle-Lamberton M, Bergot D, Gru N. Etude des travailleurs du secteur du nucléaire du groupe CEA: rapport d'avancement. Fontenay-aux-Roses, France: Rapport interne IPSN, Note SEGR 63, juillet 1998 . 